\title{
Emotional Competence in Male and Female Adolescents of Jammu and Kashmir
}

\author{
Urfain Habib $^{1}$, Dr. Omar Habib ${ }^{2}$, Prof. Shamim A. Ansari ${ }^{3}$
}

\section{ABSTRACT}

Emotional competence is the capability of handling one's emotions in varied situations. Goleman (1998) defined emotional competence as set of competencies that results in outstanding performance on job. The notion that intelligence brings with it success and achievement has taken a back seat after seeing many intelligent brains fading into oblivion and people with average intelligence ruling the world. Psychologists led by Goleman (1998) are championing the research into this area as to see; what is it that can guarantee success in life? The present research examined emotional competence in male and female adolescents of Jammu and Kashmir. Results revealed a significant difference in the emotional competence of male and female adolescents.

Keywords: Emotional Competence, Jammu and Kashmir

"If your emotional abilities aren't in hand, if you don't have self-awareness, if you are not able to manage your distressing emotions, if you can't have empathy and have effective relationships. Then no matter how smart you are, you are not going to get very far."Goleman (1998)

The very concept of emotional competence is an off shoot of 'Emotional Intelligence'. The idea of traditional types of intelligence, such as IQ, failed to fully explain cognitive ability. Thus the concept of multiple intelligence was propounded by the psychologists. Within the set of multiple intelligence, psychologists included Intra-personal (the capacity to understand one-self, to appreciate one's feelings, fears and motivations) and Inter-personal intelligence (the capacity to understand the intentions, motivation and desires of the other people). Both of these concepts of Inter-personal and Intra-personal intelligence laid the very foundation of emotional intelligence. Emotional Intelligence has been explained as the subset of social intelligence that involves the ability to monitor one's own and other's feelings and emotions, to discriminate among them and to use this information to guide one's thinking and action (Salovey \& Mayer, 2004).

\footnotetext{
${ }^{1}$ Research Scholar, AMU, Aligarh, India

${ }^{2}$ Assistant Professor, Sattam Bin Abdul Aziz, University, Al Kharj, Kingdom of Saudi Arabia

${ }^{3}$ Dean, Faculty of Social Sciences, AMU, Aligarh, India

*Responding Author

(C) 2016 U Habib, O Habib, S Ansari; licensee IJIP. This is an Open Access Research distributed under the terms of the Creative Commons Attribution License (http://creativecommons.org/licenses/by/2.0), which permits unrestricted use, distribution, and reproduction in any Medium, provided the original work is properly cited.
} 


\title{
Emotional Competence in Male and Female Adolescents of Jammu and Kashmir
}

Emotional Competence is the multi-faceted ability to strategically be aware of one's emotions and other's emotions and to act on this awareness, so that one can negotiate interpersonal exchanges and regulate emotional experience (Saarni, 1990). Constituent elements of emotional competence include abilities to:

(i) Express and experience a broad variety of well-modulated, not incapacitating, emotions.

(ii) Regulate the experience and expression of emotion- when "too much" or "too little" emotional experience, or the expression of emotions, interferes with one's intra or interpersonal goals.

(iii) Understand the emotions of one-self and others.

Thus, recommended assessment measures at all age periods, except infancy, include expression and experience, regulation, and understanding of emotions (Denham, 1998).

In the quest of strengthening the whole concept of emotional intelligence several models have been propounded by the psychologists in order to establish a general understanding of the concept. The summary of the models is given below;

\begin{abstract}
Ability Model
Mayer \& Salovey, Caruso \& Sitarenious (2001) strived to define the concept of emotional intelligence within the confines of the standard criteria for a new intelligence. Following their continuing research, their initial definition of emotional intelligence was revised to "The ability to perceive emotion, integrate emotion to facilitate thought, understand emotions and to regulate emotions to personal growth". However after pursuing research, their definition of emotional intelligence evolved into "The capacity to reason about emotions, and of emotions, to enhance thinking. It includes the abilities to accurately perceive emotions, to access and generate emotions so as to assist thought, to understand emotions and emotional knowledge, and to promote emotional and intellectual growth”(Salovey, Peter; Mayer, John; Caruso, David, 2004).
\end{abstract}

The ability based model views emotions as useful source of information that helps one to make sense of and navigate the social environment (Salovey \& Mayer, 1997; Salovey \& Grewal, 2005). The model proposes that individuals vary in their ability to process information of an emotional nature and in their ability to relate emotional processing to a wider cognition. This ability is seen to manifest itself in certain adaptive behaviors. The model claims that emotional intelligence includes four types of abilities:

1) Perceiving emotions- the ability to detect and decipher emotions in faces, pictures, voices, and cultural artefacts, including the ability to identify one's own emotions.

(c) The International Journal of Indian Psychology, ISSN 2348-5396 (e) | ISSN: 2349-3429 (p) | 6 


\section{Emotional Competence in Male and Female Adolescents of Jammu and Kashmir}

Perceiving emotions represents a basic aspect of emotional intelligence, as it makes all other processing of emotional information possible.

2) Using emotions- the ability to harness emotions to facilitate various cognitive activities, such as thinking and problem solving. The emotionally intelligent person can capitalize fully upon his or her changing moods in order to best fit the task at hand.

3) Understanding emotions- the ability to comprehend emotional language and to appreciate complicated relationships among emotions, for example, understanding emotions encompasses the ability to be sensitive to slight variations between emotions, and describe how emotions evolve over time.

4) Managing emotions- the ability to regulate emotions in both ourselves and in others. Therefore, the emotionally intelligent person can harness emotions, even negative ones, and manage them to achieve intended goals.

The current measure of ability intelligence, the Mayer-salovey-Caruso Emotional Intelligence Test (MSCEIT) is based on a series of emotion based problem solving items (Salovey \& Grewal, 2005; Bradberry \& Su, 2003). Consistent with the model's claim of emotional intelligence as a type of intelligence, the test is modeled on ability based IQ test. By testing a person's abilities on each of the four branches of emotional intelligence, it generates scores for each of the branches as well as total score. Central to the four branch model is the idea that Emotional Intelligence requires attainment of social norms. Therefore, the MSCEIT is scored in a consensus fashion, with higher scores indicating higher overlap between an individual's answers and those provided by a worldwide sample of respondents. The MSCEIT can also be expert scored, so that the amount of overlap is calculated between an individual's answers and those provided by a group of 21 emotion researches (Salovey \& Grewal, 2005).

\section{METHODOLOGY}

The sample size of the present study consisted of two hundred adolescents ( $\mathrm{N}=200)$, between the age group 16 to 19 yrs. The data has been collected from two main Senior Secondary Schools of the district Baramulla (Kashmir). For the purpose of the data collection emotional competence assessment scale was used, which has been described in detail below.

\section{EMOTIONAL COMPETENCE ASSESSSMENT SCALE (ECAS):}

The scale has been developed by Paiva and Dr. Kumar in the year 2009, which is used for all age groups. With all in all 35 items and eight dimension, each dimension consisting of 5 items. The eight dimensions of the scale are; Happiness, Love, Interest, Sympathy, Fear, Anger, Sadness and Jealousy. It is a four point scale where the subject has to choose the statement from four categories of responses namely; Always, Sometimes, Rarely and Never.

\section{RESULT AND DISCUSSION}

An independent samples t test was conducted for the purpose of data analyses.

(c) The International Journal of Indian Psychology, ISSN 2348-5396 (e)| ISSN: 2349-3429 (p) | 7 
Emotional Competence in Male and Female Adolescents of Jammu and Kashmir

Table1, Showing emotional competence of male and female adolescents

\begin{tabular}{|c|c|c|c|c|c|c|}
\hline EC & Gender & $\mathbf{N}$ & Mean & $\begin{array}{c}\text { Std. } \\
\text { Deviation }\end{array}$ & t-value & Sig \\
\hline \multirow[t]{2}{*}{ Happiness } & Male & 100 & 9.4587 & 1.72955 & 2.24 & $.01 *$ \\
\hline & Female & 100 & 9.9000 & 1.00616 & & \\
\hline \multirow[t]{2}{*}{ Love } & Male & 100 & 9.7064 & 1.71217 & -.59 & $.05 * *$ \\
\hline & Female & 100 & 9.8333 & 1.28299 & & \\
\hline \multirow[t]{2}{*}{ Interest } & Male & 100 & 9.7523 & 1.40209 & 1.99 & $.05 * *$ \\
\hline & Female & 100 & 10.1000 & 1.06053 & & \\
\hline \multirow[t]{2}{*}{ Sympathy } & Male & 100 & 19.1376 & 2.09703 & -.61 & $.01^{*}$ \\
\hline & Female & 100 & 19.3000 & 1.47983 & & \\
\hline \multirow[t]{2}{*}{ Anger } & Male & 100 & 11.6147 & 1.63247 & .71 & .07 \\
\hline & Female & 100 & 11.4667 & 1.21969 & & \\
\hline \multirow[t]{2}{*}{ Sadness } & Male & 100 & 11.0367 & 1.91933 & .41 & .27 \\
\hline & Female & 100 & 10.9333 & 1.55643 & & \\
\hline \multirow[t]{2}{*}{ Jealousy } & Male & 100 & 11.0367 & 1.73166 & -.73 & .12 \\
\hline & Female & 100 & 11.2000 & 1.29996 & & \\
\hline \multirow[t]{2}{*}{ EC.Total } & Male & 100 & 81.5963 & 8.55388 & 9.74 & $.05 * *$ \\
\hline & Female & 100 & 93.6000 & 8.72913 & & \\
\hline
\end{tabular}

Note: ${ }^{*} \mathrm{p}<.01,{ }^{* *} \mathrm{p}<.05$, EC $=$ Emotional Competence

The results revealed that male and female adolescents differ significantly in respect to their Emotional Competence, with t-value of 9.74 and $\mathrm{p}=.05$. Female adolescents $(\mathrm{M}=93.60)$ exhibit higher score of Emotional Competence than their Male counterparts ( $M=81.59$ ). Examination of the various dimensions of Emotional Competence further revealed Female adolescents scored significantly high on three dimensions of Emotional Competence (Happiness: $M=9.90$, Love: $M=9.83$ \& Interest: $M=10.10$ ). Dimension wise analyses of emotional competence revealed that male and female adolescents do not differ on the following dimensions viz; anger, sadness \& jealousy, but they do differ on the dimensions of happiness, love, interest and sympathy. The findings are backed by the study conducted by Brody and Hall (2000), where they found that women are more emotionally expressive than men. Being emotionally expressive is an integral part of emotional competence.

\section{Acknowledgments}

The author appreciates all those who participated in the study and helped to facilitate the research process.

(C) The International Journal of Indian Psychology, ISSN 2348-5396 (e)| ISSN: 2349-3429 (p) | 8 


\section{Emotional Competence in Male and Female Adolescents of Jammu and Kashmir}

\section{Conflict of Interests}

The author declared no conflict of interests.

\section{REFERENCES}

Bradberry, T., \& Su, L. (2003). Ability-Versus Skill-based assessment of emotional Intelligence. Psicothema,18, 59-66.

Brody, L.R. and Hall, J.A. 2000. Gender, Emotion, and Expression. In Handbook of Emotions, ed. by M. Lewis and J.M. Haviland-Jones. 2nd ed. New York: Guilford.

Denham, S.A. (1998). Emotional development in Young Children, New York. Guilford Press.

Goleman, D. (1998). Working with emotional intelligence. New York. Bantam Books.

Mayer, J.D., Salovey, P., Caruso, D.L., \& Sitarenioes, G. (2001). Emotional intelligence as a standard intelligence. Emotion, 1, 232-242.

Paiva, J. S. F., \& Kumar, M. S. (2009). Emotional Competence Assessment Scale. Retrieved from maduraipsychologist.blogspot.com. Retrived on 17th Feb. 2013.

Saarni, C. (1990). Emotional Competence. In Ross Thompson (Eds), Nebraska Symposium: Socioemotional development (pp. 115-161). Lincoln, NE: University of Nebraska Press.

Salovey, P., \& Grewal, D (2005). The science of Emotional Intelligence. Current directions in Psychological Science.

Salovey, P., Mayer, j., \& Caruso, D. (2004). Emotional intelligence: Theory, Finding and Implications. Psychological Inquiry, 197-222.

Salovey, P., Mayer, J., Caruso, D., \& Lopes, P. (2004). Measuring emotional intelligence as a set of abilities with the MSCEIT. In S.J. Lpez \& C.R. Synder (Eds.) Handbook of positive psychology assessment. Washington, DC. American Psychological Association

How to cite this article: U Habib, O Habib, S Ansari (2016), Emotional Competence in Male and Female Adolescents of Jammu and Kashmir, International Journal of Indian Psychology, Volume 4, Issue 1, No. 79, ISSN:2348-5396 (e), ISSN:2349-3429 (p), DIP:18.01.081/20160304, ISBN:978-1-365-56745-2 